\title{
PERSONAS SEPARADAS ACTUANDO EN CONJUNTO. UN ESBOZO DE TEORÍA DEL DERECHO CONTRACTUAL *
}

\author{
Martín Hevia \\ Universidad Torcuato Di Tella (Argentina)
}

RESUMEN. Este ensayo aborda el siguiente interrogante: si, como famosamente sostuvo John RAWLS, la justicia es la virtud fundamental de las instituciones sociales, ¿cómo debemos entender al derecho de los contratos? En este ensayo sitúo el derecho de los contratos en los términos de lo que John RaWLS llama «la división social de la responsabilidad». Según esta idea, la sociedad como un todo debe proveer a los individuos de una cantidad adecuada de recursos y oportunidades necesarios para establecer y promover su propia concepción del bien. Una vez que los individuos tienen una porción justa, los ciudadanos tienen que hacerse cargo de sus propias vidas. Un modo en el que las personas llevan a cabo sus planes es a través de acuerdos con otras personas. Esto requiere un sistema de reglas contractuales. Mi argumento es que la justicia requiere entender las reglas contractuales en términos de la idea de condiciones justas de interacción -es decir, condiciones aceptables para personas razonables movidas por el deseo de un mundo social en el que, como libres e iguales, puedan cooperar con otros en los términos que acepten-. La idea subyacente es la de la reciprocidad, esto es, la idea de que los individuos no deben establecer unilateralmente las condiciones de su interacción con otros. Así, en este ensayo sugiero que las interacciones contractuales deben enfocarse desde la perspectiva de la persona razonable. $\mathrm{Mi}$ objetivo es explicar la formación de un contrato, la respuesta jurídica frente al incumplimiento contractual y otras cuestiones que surgen con las interacciones contractuales desde esa perspectiva.

Palabras clave: personas razonables, RAWLS, contratos.

ABSTRACT. This paper explores the following question: if, as John RAWLS famously suggests, justice is the first virtue of social institutions, how are we to understand the institution of contract law? In this paper, I situate contract law in terms of what John RAWLS calls «the social division of responsibility": society as a whole has to provide individuals with an adequate share of opportunities and resources that they need in order to set and pursue their own conception of the good. Once individuals have those fair shares, citizens have to take responsibility for how their own lives go. An important way that people may pursue their plans is by entering into arrangements with others. This requires a system of contract rules. I argue that justice requires that we understand contract rules in terms of the idea of fair terms of interaction -that is, terms that would be accepted by reasonable persons moved by a desire for a social world in which they, as free and equal, can cooperate with others on terms they accept. The underlying idea is that of reciprocity, that is, the idea that individuals should not set the terms of their interactions with others unilaterally. This means that the particular idiosyncrasies of individuals are not supposed to unilaterally set the conditions of people's private interactions with one another. In this paper, I claim that contractual interactions should be approached from the perspective of the reasonable person. My aim is to explain the formation of a contract, the legal response to a breach, and other issues that come up with contractual interactions from that perspective.

Key words: reasonable persons, RAwLS, contracts.

\footnotetext{
* Fecha de recepción: 27 de marzo de 2009. Fecha de aceptación: 30 de abril de 2009.

Escuela de Derecho, Universidad Torcuato Di Tella (Argentina). Este trabajo se publicó originariamente en inglés en Canadian Journal of Law E Jurisprudence, vol. 12, núm. 2, 2009.
} 
«La justicia es la primera virtud de las instituciones sociales, así como la verdad lo es de los sistemas de pensamiento. Una teoría, por elegante y concisa que sea, debe ser rechazada o revisada si es falsa. Del mismo modo, las leyes y las instituciones, no importa cuán eficientes y bien ordenadas estén, deben ser reformadas o abolidas si ellas son injustas» ${ }^{1}$.

«Es lo razonable lo que nos hace entrar como iguales al mundo público de los demás y que nos disponemos a proponer, o a aceptar, según el caso, términos de cooperación justa» ${ }^{2}$.

John RAWLS

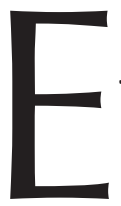

ste ensayo aborda el siguiente interrogante: si, como famosamente sostuvo J. RAWLS, la justicia es la virtud fundamental de las instituciones sociales, ¿cómo debemos entender al derecho de los contratos? Por un lado, muchos autores sostienen que las reglas del derecho contractual son meras herramientas para promover la justicia distributiva ${ }^{3}$; por el otro, algunos autores libertarios sostienen que las reglas contractuales no dejan espacio alguno para la idea de justicia distributiva ${ }^{4}$. En este ensayo propongo un enfoque alternativo. Situó el derecho de los contratos en los términos de lo que J. RAWLS llama «la división social de la responsabilidad». Según esta idea, la sociedad como un todo debe proveer a los individuos de una cantidad adecuada de recursos y oportunidades necesarios para establecer y promover su propia concepción del bien. Una vez que los individuos tienen una porción justa, los ciudadanos tienen que hacerse cargo de sus propias vidas. Un modo en el que las personas llevan a cabo sus planes es a través de acuerdos con otras personas. Esto requiere un sistema de reglas contractuales. Mi argumento es que la justicia requiere entender las reglas contractuales en términos de la idea de condiciones justas de interacción —es decir, condiciones aceptables para personas razonables movidas por el deseo de un mundo social en el que, como libres e iguales, puedan cooperar con otros en los términos que acepten-. La idea subyacente es la de la reciprocidad, esto es, la idea de que los individuos no deben establecer unilateralmente las condiciones de su interacción con otros. Las condiciones justas de interacción son condiciones razonables ${ }^{5}$. Mi argumento central es que las interacciones contractuales están basadas en lo que es justo para las personas que interactúan con otros, y no en lo que es justo desde el punto de vista subjetivo de cada individuo. Así, en este ensayo sugiero que las interacciones contractuales deben enfocarse desde la perspectiva de la persona razonable. Mi objetivo es explicar la formación de un contrato, la respuesta

1 J. Rawls, A Theory Of Justice, ed. rev., Cambridge, Mass., Harvard University Press, 1999, p. 3.

2 J. RaWLs, Political Liberalism, New Cork, Columbia University Press, 1993, p. 53.

3 Vid., por ejemplo, A. Kronman, «Contract Law and Distributive Justice», Yale L.J., 472, 1980, p. 89; Kordana y D. TABACHNIK, «Rawls and Contract Law», Geo. Wash. L. Rev., 701, 2005, p. 73; «On Belling the Cat: Rawls and Tort as Corrective Justice», Va. L. Rev., 1279, 2006, p. 92. Para una discusión respecto del enfoque distributivo de los contratos, ver «Kronman on Contract Law and Distributive justice», Journal of Contractual Law, 105, 2007, p. 23.

4 Vid., por ejemplo, R. BARnetT, «A Consent Theory of Contract», Colum. L. Rev., 269, 1986, p. 86, .

5 A. RIPSTEIn, Equality, Responsibility, and the Law, Cambridge, UK, Cambridge University Press, 1999, p. 206. 
jurídica frente al incumplimiento contractual y otras cuestiones que surgen con las interacciones contractuales desde esa perspectiva.

Este ensayo está dividido en dos partes. La primera establece los fundamentos de mi teoría rawlsiana del derecho de los contratos y procede de la siguiente manera: En la Sección I, empiezo por introducir la idea rawlsiana de la sociedad como sistema justo de cooperación social que va de generación en generación. Luego, explico que esta idea debe entenderse en los términos de dos ideas conjuntas: por un lado, la noción de una sociedad bien ordenada — esto es, una sociedad donde los individuos están dispuestos a actuar sobre la base de principios públicos de justicia siempre que otros estén también dispuestos a hacerlo-; por el otro lado, la idea de personas como ciudadanos libres e iguales que no sólo son racionales sino también razonables - lo que significa que pueden actuar sobre la base de los principios públicos de justiciaEn la última parte de esa sección, amplío la distinción entre las ideas complementarias de lo razonable y lo racional. Lo razonable está conectado con la capacidad que los ciudadanos tienen de tener un sentido de qué es lo justo; lo racional, en cambio, se conecta con la capacidad de adoptar una concepción del bien, sea cual sea esa la concepción del bien que se adopte. La Sección II describe cómo esta concepción rawlsiana del individuo incluye la idea de una división de responsabilidad tal como la presenta RAWLS en «Unidad Social y Bienes Primarios». Como explicaré luego, la división de responsabilidad tiene dos dimensiones normativas. La primera se refiere al deber de la sociedad de proveer a los individuos con recursos y oportunidades que les permitan establecer y perseguir sus propios planes; el segundo aspecto trata sobre la forma en que, como ciudadanos, debemos interactuar los unos con los otros. En la Sección III, expongo el derecho contractual en los términos de lo que llamo deberes relacionales, esto es, deberes que, dentro de la división de responsabilidad, nos debemos los unos a los otros cuando voluntariamente decidimos cooperar mediante acuerdos personales. La Sección IV explica la idea de que un contrato da lugar a un derecho personal —esto es, un derecho in personam - del acreedor contra su deudor. En la Sección V, discuto el siguiente interrogante: si las personas son libres de firmar contratos como les parezca conveniente, y en la medida en que un contrato se traduce en una redistribución de bienes de una parte a la otra, ¿qué ocurre si la distribución que resulta es desigual? Con el fin de responder este interrogante introduzco lo que RAWLS llama la «división institucional del trabajo» entre los principios que rigen para organizar la estructura básica y las reglas que se aplican directamente a los individuos y asociaciones y que deben seguirse en las transacciones particulares, esto es, cuando éstos celebran acuerdos. Expongo cómo esta división puede explicarse en términos de dos dimensiones diferentes de la división de responsabilidad.

En la segunda parte de este ensayo, explico los fundamentos rawlsianos del estándar de la persona razonable. En particular, la Sección VI describe cómo esta idea puede ser utilizada para explicar distintas doctrinas contractuales. Más específicamente, comparo el estándar objetivo para la formación del contrato con el enfoque subjetivo que caracteriza al enfoque francés del Derecho privado. En la Sección VII, en contra de los comunitaristas y feministas, sostengo que esta idea rawlsiana brinda una justificación mejor para el uso legítimo de la coerción estatal que otras alternativas propuestas. Finalmente, en la Sección VIII ofrezco una conclusión. 


\section{PARTE PRIMERA}

\subsection{La sociedad como sistema justo de cooperación social}

El punto de partida de RAWLS es una idea organizativa fundamental: RAWLS ve a la sociedad como sistema justo de cooperación social en el tiempo de una generación a la otra. «Cooperación» no es lo mismo que «mera actividad socialmente coordinada». Cuando los individuos cooperan entre sí, lo hacen bajo la dirección de reglas «públicas» que aquellos que cooperan aceptan y consideran apropiadas. Por términos «justos» de cooperación, RAWLS quiere decir que esos términos son tales que cada participante puede razonablemente aceptarlos, siempre que el resto de las personas los acepten y respeten. Un aspecto importante de este enfoque de la cooperación es que las normas «públicas» expresan un sentido de reciprocidad: todos están dedicados al beneficio de la cooperación desde el orden social «en alguna forma adecuada según la evaluación de un adecuado punto de referencia de comparación» ${ }^{6}$. Su idea de un sistema de cooperación social justa debe entenderse a la luz de otras dos ideas complementarias fundamentales: la idea de una sociedad bien ordenada y la de una concepción específica de la persona, esto es, la idea de ciudadanos como personas libres e iguales. Vayamos por partes.

Consideren la noción de una sociedad bien ordenada. Esta noción tiene tres características fundamentales. Primero, en una sociedad bien ordenada, todos aceptan y saben que todos los demás aceptan la misma concepción política de justicia. Esto no quiere decir que todos comparten la misma concepción «comprehensiva» del bien; sólo significa que todos aceptan los mismos principios públicos de justicia. Segundo, las principales instituciones políticas y sociales de una sociedad bien ordenada están organizadas de acuerdo a esos principios públicos de justicia, independientemente de cuáles sean. Tercero, en una sociedad bien ordenada, los ciudadanos son capaces de entender y aplicar esos principios públicos de justicia. En resumen, como dice el propio RAWLS,

«en una sociedad bien ordenada, entonces, la concepción pública de justicia proporciona un punto de vista mutuamente reconocido a partir del cual los ciudadanos pueden resolver sus reclamos de Derecho político en sus instituciones políticas y uno en contra del otro» ${ }^{7}$.

La noción de una sociedad bien ordenada se adapta a una concepción particular de la persona. RAWLS explica que es crucial entender que la concepción de la persona en juego no deriva ni de la metafísica ni de la filosofía de la mente ni de la psicología. Más aún, no esta necesariamente relacionada con la concepción del ser humano - miembro de la especie homo sapiens - tal como se lo entiende en biología o psicología ${ }^{8}$. La concepción de la persona es normativa y política ${ }^{9}$. Para RAWLS, esta concepción de la persona es familiar a todos nosotros:

\footnotetext{
6 Rawls, «Justice as Fairness: Political not Metaphysical», en S. FreEman (ed.), J. Rawls: Collected Papers, Cambridge, Mass., Harvard University Press, 1999, pp. 388 a 396.

7 RaWls, Justice as Fairness - A Restatement, Cambridge, Mass., The Belknap Press of The Harvard University Press, 2001, p. 9.

8 Ibid., p. 24.

9 Por «normativa», RAWLS quiere decir son tomadas con ciertas características particulares. Por «politicas», RAWLS no quiere decir que el contenido de esta concepción de la persona se discuta en asambleas
} 
«Desde la antigua Grecia, tanto en filosofía como en Derecho, el concepto de persona ha sido el de alguien que puede tomar parte, o desenvolver un rol en la vida social y por lo tanto, ejercer y respetar todos sus derechos y deberes» ${ }^{10}$.

Esta concepción política de la persona presupone que los individuos tienen los dos siguientes poderes morales ${ }^{11}$ :

a) El primer poder es la capacidad de desarrollar un sentido de justicia: es la capacidad de entender, de aplicar, y actuar motivado por —y no sólo de conformidad con- los principios de justicia política que especifican los términos justos de cooperación social.

b) El otro poder moral es una capacidad para desarrollar una concepción del bien: es la capacidad de formar, revisar, y perseguir racionalmente una concepción de lo bueno. Como explica RAWLS,

«[e]sa concepción es un conjunto ordenado de los fines y objetivos finales que especifican la concepción personal de lo que es de valor en la vida humana o, alternativamente, lo que se considera una vida que vale la pena. Los elementos de tal concepción se fijan en el interior, y son interpretados por ciertas doctrinas comprehensivas, religiosas, filosóficas, o morales a la luz del modo en que se ordenan y se entienden los diversos fines y objetivos» ${ }^{12}$.

Al decir que las personas son consideradas poseedoras de los dos poderes morales, estamos diciendo que tienen las capacidades necesarias no sólo para participar en la cooperación social mutuamente beneficiosa a través de una vida completa sino también para motivarse para honrar a sus condiciones justas por su propio bien.

En esta concepción de la persona, las personas son libres e iguales. Primero, los individuos son libres en la medida en que se conciben a sí mismos y los unos a los otros como teniendo el poder moral de desarrollar una concepción de lo bueno. Este poder a su vez conlleva su capacidad de revisar su propia concepción de lo bueno en la medida en que lo consideran necesario ${ }^{13}$.

Los ciudadanos son también libres en un segundo modo: «son considerados capaces de hacerse responsable de sus objetivos, y esto afecta a la forma en que se evalúan sus distintos reclamos» ${ }^{14}$. Pero no sólo eso: los ciudadanos se ven a sí mismos con el

democráticas, ni que es el resultado inevitable de luchas partidistas por poder. En cambio, quiere decir que la concepción de la persona es específica de la moralidad política y no dependiente de un enfoque moral o político más comprehensivo. En este contexto, luego, «política» significa «para los fines de los estándares públicos» en oposición a privados o finales. Ver RIPSTEIN, supra, nota 5, p. 12, n. 8.

10 RAWLS, cit. supra, nota 7, p. 24.

11 Ibid., pp. 18-19.

12 Ibid., p. 19. Estos dos poderes deben ser complementados con lo que RaWLS llama «poderes de la razón». Estos poderes son aquellos del juicio, el pensamiento, y de la inferencia. Son poderes que son esenciales a los dos poderes y requeridos para su ejercicio. Ver también RAWLS, supra, nota 2, p. 19.

13 También es importante notar que incluso si las personas cambian su concepción del bien, su identidad pública o legal como personas libres, no se ve afectada por esos cambios. La gente puede cambiar su afiliación política o religiosa. Por ejemplo, como dice RAWLS, «[e]n ruta a Damasco Saúl de Tarso se convierte en Pablo el Apóstol». Sin embargo, sus derechos y deberes básicos no se ven afectados. Además, incluso si cambian de religión o inclinación política, están facultados para hacer los mismos reclamos que podían hacer antes de que esos cambios tuvieran lugar. Ver RAWLS, cit. supra, nota 7, p. 23.

14 RaWls, «Justice as Fairness: Political not Metaphysical», en S. FreEMAN (ed.), John Rawls: Collected Papers, Cambridge, Mass., Harvard University Press, 1999, pp. 388 a 407. 
derecho a presentar reclamos en sus instituciones sociales para que puedan seguir su propia concepción de lo bueno ${ }^{15}$.

He dicho que en este esquema rawlsiano se considera a las personas como libres, pero no sólo eso: también son consideradas iguales. Son iguales en el sentido que, como RAWLS explica, «todos ellos son considerados con el grado mínimo esencial de poderes morales necesarios para participar en la cooperación social a través de una vida completa y para tomar parte en la sociedad como ciudadanos en pie de igual$\mathrm{dad} \gg^{16}$. Noten que RAWLS se refiere a la capacidad y no a su realización ${ }^{17}$. Esto significa que, incluso si, como una cuestión de hecho, la capacidad no se desarrolla, todos los seres son tomados como poseedores de esta capacidad y en consecuencia, con el derecho a reclamar su parte justa de sus instituciones sociales y políticas ${ }^{18}$. Además, algunas personas pueden tener una mayor capacidad para el sentido de justicia -les puede resultar más fácil aplicar los principios de justicia— pero esa mayor capacidad es «un activo natural como cualquier otra habilidad» ${ }^{19}$.

Las personas rawlsianas son racionales y razonables. Son racionales porque son capaces de perseguir cualquier fin que elijan por sí mismos. Además de ser racionales, las personas rawlsianas son razonables. Así, tienen el «deseo de participar en una cooperación justa» ${ }^{20}$. Las personas razonables son aquellas que están dispuestas a actuar sobre la base de un principio que otros puedan aceptar - y que por lo tanto, los otros puedan encontrar justificable-; las personas razonables también están dispuestas a discutir los términos justos de interacción que otros propongan. Las personas razonables, sin embargo, no son altruistas en el sentido de que desean el bien general en sí mismo; lo que las personas razonables quieren es un mundo donde, como individuos libres e iguales, puedan cooperar con otras sobre la base de términos que todos puedan aceptar, es decir, sobre la base de términos justos de interacción ${ }^{21}$. En cambio, las personas irrazonables actúan oportunístamente: «pueden planear participar en planes de cooperación, pero no están dispuestos a honrar, o incluso a proponer, con excepción de una necesaria pretensión pública, ningún principio general o normas para especificar los términos justos de interacción. Están dispuestos a violar los términos que se adapten a sus intereses cuando las circunstancias lo permitan ${ }^{22}$.

La razonabilidad y la racionalidad son dos ideas diferentes pero, dentro de la idea de cooperación justa, son complementarias ${ }^{23}$. Lo razonable y lo racional son elementos de la idea fundamental de los términos justos de cooperación. Cada uno de ellos se conecta con su distintivo poder moral. Lo razonable se conecta con la capacidad

15 Ibid.

16 Ibid., p. 20.

17 Ver RAWLS, supra, nota 1, p. 445.

18 Ibid., p. 443.

19 Ibid.

20 RaWls, supra, nota 2, p. 51. Es importante notar que, en su A Theory Of Justice, RaWLs sostuvo algo de lo que se arrepintió posteriormente. Había dicho que «la teoría de la justicia es una parte, tal vez la más significante, de la teoría de la elección racional». Ver RAWLS, supra, nota 2, p. 16. Más tarde, RAWLS rechazó esta aseveración porque creyó que llevaría a la idea engañosa de que todo en su enfoque de la justicia distributiva estaba basado en nociones de racionalidad.

21 RAWLS, supra, nota 2, p. 50.

22 Ibid.

23 Ibid., p. 52. 
por un sentido de justicia; lo racional, en cambio, se conecta con la capacidad por una concepción del bien ${ }^{24}$.

Ahora, la concepción rawlsiana de persona incluye lo que RAWLS llama «una división social de responsabilidad». Permítanme explicar a continuación esta idea en detalle.

\subsection{La división de la responsabilidad}

En «Unidad social y bienes primarios», RAWLS explica la idea de la división de la responsabilidad del siguiente modo:

«La sociedad, los ciudadanos como un cuerpo colectivo, aceptan la responsabilidad de mantener la igualdad de las libertades fundamentales y la igualdad de oportunidades justas mientras los ciudadanos (como individuos) ... aceptan la responsabilidad de revisar y ajustar sus fines y aspiraciones en vista de todos los medios que sirven para perseguir fines que puedan esperar, dada su situación presente y previsible. Esta división de responsabilidad confía en la capacidad de las personas de asumir la responsabilidad respecto de sus fines y moderar los reclamos que realizan ante sus instituciones sociales de conformidad con el uso de bienes primarios. Los reclamos de los ciudadanos frente a las libertades, oportunidades, y todos los medios necesarios para perseguir fines están protegidos de las demandas irrazonables de los otros» ${ }^{25}$.

Este pasaje sugiere la existencia de dos dimensiones de la división de la responsabilidad. Los individuos libres e iguales deben tomar responsabilidad por aquello que hacen con sus propias vidas pero, al mismo tiempo, la sociedad como un todo tiene el deber de asegurar que los individuos tengan la oportunidad de llevar una vida exitosa: los individuos deben tener aquellos recursos y oportunidades que les permitan establecer y perseguir sus planes. En este marco, el contenido específico de los planes que adopta cada individuo es irrelevante: mientras no interfieran con las elecciones de otros, los individuos deben ser libres de hacer lo que crean adecuado ${ }^{26}$.

La división de la responsabilidad, entonces, da lugar a determinados tipos de deberes. En primer lugar, están los deberes de los individuos de apoyar instituciones justas. Esos son deberes que los individuos tienen con la sociedad en general, y no con alguien en particular. Estos deberes son, entonces, deberes no relacionales. Además,

24 Ibid.

25 J. RAWLS, «Social Unity and Primary Goods», en A. SEN y B. WiLliams (eds.), Utilitarianism and Beyond, Cambridge, UK, Cambridge University Press, 1982, pp. 159 a 170.

26 A. RIPSTEIn, «Private Order and Public Justice: KANT and RAWLS», Va. L. Rev., 1391, 2006, p. 92. T. M. SCANLON explica la división de responsabilidad del siguiente modo:

«La idea es la siguiente. La "estructura básica” de la sociedad es su sistema legal, político y económico, cuya función es definir las posiciones en que los diferentes poderes y los beneficios económicos se adjuntan. Si una estructura básica hace esto de un modo aceptable — si los ciudadanos no tienen quejas razonables respecto de su acceso a distintas posiciones dentro de este esquema o al paquete de derechos, libertades, y oportunidades frente a recompensas económicas que presentan ciertas posiciones en particular- entonces la estructura es justa. Corresponde a las personas, operando dentro de este esquema, elegir sus propios fines y hacer uso de las oportunidades dadas y recursos para perseguir esos fines lo mejor que puedan. El éxito o el fracaso, la felicidad o la infelicidad será un resultado de su propia responsabilidad».

Ver T. M. Scanlon, What We Owe to Each Other, Cambridge, Mass., Harvard University Press, 1998, p. 244. 
hay deberes que la sociedad tiene con los individuos ${ }^{27}$. Quisiera sugerir que la división de la responsabilidad da lugar además, a otro tipo de deberes, deberes relacionales, esto es, deberes que los individuos tienen con otros individuos. A continuación mostraré que las obligaciones contractuales son de este tipo.

De acuerdo con la concepción rawlsiana de justicia, las personas deben gozar de libertades iguales y de igualdad de oportunidades justas que les permitan establecer y perseguir sus propios planes. RAWLS se refiere a esos medios como «bienes primarios». Es por eso que los bienes primarios son llamados «medios que sirven para perseguir cualquier fin» ${ }^{28}$. Ahora, dado que son razonables, se asume que las personas son capaces de regular y revisar sus objetivos a la luz de sus expectativas legítimas: los individuos tienen la capacidad de asumir responsabilidad por sus fines: no son portadores pasivos de deseos ${ }^{29}$. En este marco, los individuos pueden tener reclamos contra la sociedad en general; pueden demandar los bienes primarios que, desde una perspectiva objetiva, son necesarios para establecer y perseguir sus planes. Esta es la idea de cantidad justa de bienes. Luego, un índice de bienes primarios es adoptado como parte de los principios de justicia. Una vez que esto está en práctica, puede usarse para caracterizar qué tipos de reclamos de recursos sociales son apropiados. En consecuencia, los bienes primarios son de ayuda para establecer un estándar público que cualquiera pueda aceptar ${ }^{30}$. Entonces, por ejemplo, las libertades básicas son bienes primaros. En el modelo rawlsiano, la gente tiene un derecho a que se no violen sus libertades básicas. Como sostiene RAWLS,

«Las libertades básicas son inalienables y, por tanto, no pueden ni ser objeto de renuncia ni limitadas por los acuerdos realizados por los ciudadanos, ni ser anuladas por preferencias colectivas compartidas... cualquier intento de renuncia o de infringirlas están prohibidos ab-initio; los deseos de los ciudadanos al respecto no tienen fuerza legal y no deben afectar a estos derechos. Tampoco deben, no obstante los deseos de cualquier otro de denegar o limitar la igualdad de las libertades básicas de una persona, tener peso alguno. Las preferencias que pueden tener este efecto nunca entran, por así decirlo, dentro del cálculo social» ${ }^{31}$.

Permítanme ahora pasar a la otra dimensión de la división de responsabilidad. Esta otra dimensión puede explicarse en términos de las responsabilidades entre ciudada-

27 Tomo prestado este punto de A. RiPSTEIN, «The Division of Responsibility and the Law of Tort», 200472 Fordham L. Rev., p. 1811

28 RAWLS, nota supra 7, p. 169.

29 Ibid.

30 RAWLS caracteriza la lista de bienes primarios del siguiente modo:

- Primero, las libertades básicas: libertad de pensamiento y libertad de conciencia; libertad de asociación; y la libertad definida por la libertad e integridad de la persona, así como también por el estado de derecho; y, finalmente, las libertades políticas;

- Segundo, libertad de movimiento y elección de ocupación contra un trasfondo de oportunidades diversas;

- Tercero, poderes y prerrogativas de oficinas y posiciones de responsabilidad, particularmente aquellas en las principales instituciones políticas y económicas;

- Cuarto, ingresos y riquezas (teniendo un valor de cambio) que se necesitan para alcanzar los diferentes fines que las personas puedan aprobar; y

- Finalmente, las bases sociales del auto-respeto a sí mismos (es decir, cosas como la realidad institucional de que las personas tienen derechos básicos iguales y que todos apoyan las instituciones sociales).

Ver RAWLS, supra, nota 7, pp. 58-60.

31 RAWLS, supra, nota 25, p. 171, n. 11. 
nos. La idea principal es que, debido a que los particulares son libres para perseguir sus propios fines, sólo pueden hacerlo en la medida en que permitan a otros perseguir sus propios planes al mismo tiempo. Ésta es una idea de igual libertad: si mi vida es mi responsabilidad, entonces otros no deberían interferir con ella. Pero, al mismo tiempo, no debería desplazar los costos de mis actividades a otros: debo hacerme responsable de mi propia vida, y ellos deben hacerse responsables de la suya - pero no por mis hechos ${ }^{32}$ - . Ahora, ¿existe un espacio para las normas contractuales en este marco? Me referiré a esta cuestión en la próxima sección.

\subsection{Deberes relacionales, privados y Derecho contractual}

He dicho que las personas racionales tienen sus propios fines que perseguir. Las personas están interesadas en tener recursos y oportunidades precisamente porque pueden establecer y perseguir las diferentes concepciones de lo bueno que puedan adoptar. Por eso, deben ser capaces de hacer lo que quieran con sus vidas bajo los requerimientos de igual libertad: no tendría sentido darles recursos y luego no permitirles que dispongan de ellos de acuerdo a sus planes. Ahora, una de las formas en que las personas pueden querer perseguir sus planes es mediante acuerdos con otros. Como he dicho, por ejemplo, las personas deben poder tener la opción de intercambiar bienes con otros, de realizar un servicio para ellos o de dar regalos. También he dicho que, como las personas pueden tener planes distintos, deben ser capaces de transferir los derechos antes de la entrega efectiva de la cosa o antes de que el servicio en cuestión se realice. Eso les permitirá planificar con antelación. El derecho contractual es un modo de bacer todo esto: es un modo de subordinar nuestros bienes a nuestra propia concepción del bien ${ }^{33}$.

De nuevo, cuando la gente celebra contratos, coopera en proyectos particulares, de manera que cada persona pone sus competencias a disposición de otros. Ésta es una característica importante de la idea rawlsiana de «establecer y perseguir» una concepción de lo bueno. El hecho de que las personas puedan tener la conducta futura de otras a su disposición es otra forma de permitirles establecer sus propios objetivos. Visto de esta manera, la posibilidad de celebrar contratos aumenta su capacidad para alcanzar los objetivos que se fijaron. Al mismo tiempo, cuando las personas persiguen sus propios planes de este modo, la idea de igual libertad requiere que cumplan los términos de sus acuerdos. Si no lo hicieran, no estarían tomando responsabilidad por su propia vida. Además, si $\mathrm{A}$ incumple un contrato que tiene con $\mathrm{B}$ y no se exige que pague un costo por su incumplimiento, A estaría estableciendo los términos de la relación contractual unilateralmente porque estaría privando a $\mathrm{B}$ de algo a lo que éste tiene un derecho - esto es, el cumplimiento de A.

En la siguiente sección, me dedicaré a la tarea de decir más sobre el modo en que mi enfoque rawlsiano explica la naturaleza de los contratos.

32 Noten que, hasta ahora, sólo hice referencia a planes de vida de los individuos. Ello no significa que tales planes sean necesariamente individualistas: las personas pueden elegir perseguir sus planes afiliándose a diferentes grupos y asociaciones. Ver RAWLS, «Fairness to Goodness», en RAWLS, supra, nota 6, p. 273.

33 A. RIPSTEIN, supra, nota 28, p. 1838. 


\subsection{Los fundamentos de la doctrina de los contratos}

Dentro de la división de responsabilidad, al concluir acuerdos, las personas pueden ejercer su derecho de elegir cooperar con otros voluntariamente. Pero, por supuesto, también pueden optar por no hacerlo. Nadie puede ser obligado a concluir contratos con otros: las obligaciones contractuales son obligaciones voluntarias. El derecho contractual es una herramienta que podemos usar voluntariamente para perseguir nuestros objetivos. Es por ello que el consentimiento de ambas partes es crucial para la existencia del contrato. Cuando pensamos en las obligaciones que adoptamos voluntariamente, pensamos en términos de una interacción transaccional entre las partes. Sólo las personas entre las cuales una oferta contractual y su aceptación tuvieron lugar - esto es, las partes en un contrato- pueden exigir el cumplimiento del contrato $^{34}$. Las obligaciones voluntarias son obligaciones que uno contrae con personas particulares. Un contrato da lugar a un régimen de derechos y deberes correlativos. Ésta es la naturaleza transaccional de los derechos contractuales, que explica el tipo de derecho que el promitente adquiere del promisario. En términos legales usuales, los contratos dan nacimiento a derechos in personam, derechos que un individuo tiene vis a vis con otro individuo. Un derecho in personam es completamente transaccional. Los derechos contractuales son derechos in personam: sólo dan nacimiento a un deber correlativo en la persona que queda obligada directamente por el acuerdo. Esos derechos son también denominados «derechos personales». En el derecho contractual, un derecho personal es un derecho que el titular (una de las partes en el contrato) tiene frente a la otra parte en particular. El titular de un derecho in personam sólo puede oponer ese derecho a la persona que tiene un deber correlativo ${ }^{35}$.

La naturaleza correlativa de los contratos también explica qué pasa cuando se incumple un contrato. Dado que el promisario le debe algo al promitente, y no a otro, o a la sociedad en su conjunto, sólo la víctima del incumplimiento puede exigir una compensación. Por el contrario, dado que sólo el promitente, y no otra persona, tie-

34 Este punto es tratado por S. SMITH, quien desarrolla esta explicación en el contexto de su discusión de los contratos en beneficio de terceros. Ver S. SMITH, «Contracts for the Benefit of Third Parties: In Defence of the Third-Party Rule», 17 O.J.L.S., 1997, p. 643.

${ }^{35}$ Usualmente, el Derecho distingue entre derechos in personam y los derechos in rem, que son derechos de propiedad. Por oposición a los contratos in personam, los derechos in rem son exigibles donde quiera que la cosa en juego se encuentre y, por lo tanto, son exigibles contra cualquiera en posesión de la cosa o que interfiera con ella. Un derecho in rem no tiene naturaleza transaccional. Por supuesto, al igual que los derechos personales, los derechos in rem pueden adquirirse por la interacción entre las partes. Por ejemplo, un derecho in rem puede nacer cuando adquiero algo de mi vecino. Pero, contrariamente a los derechos in personam, la existencia del derecho in rem sobre la cosa no está limitado a la interacción entre mi vecino yo.

Desde la perspectiva rawlsiana, los derechos in rem pueden ser entendidos del siguiente modo. En orden de perseguir sus fines, las personas necesitan ser capaces de adquirir sus medios. Pero también necesitan ser protegidas contra cualquier infracción a los derechos que tengan sobre esos medios. Para que exista esa protección, debe existir un sistema de límites recíprocos a la libertad que se apliquen a todos. Debe asegurarse a las personas que los otros se abstendrán de interferir con sus posesiones o, de lo contrario, no habrá nada malo en interferir con esas posesiones. Tengo un derecho contra todas las personas a través de algo que involucra a todos. Ese es un sistema legal general que incluye derechos de propiedad oponibles. En contraste, tengo un derecho personal contra mi vecino a través de un hecho afirmativo de su parte. Debe haber algo que nos obligue a los dos juntos, y no al resto del mundo. Para que nazca mi derecho personal contra mi vecino debe haber una transacción entre ambos. 
ne frente al promisario un deber, será el encargado de compensar ante su eventual incumplimiento. Esta es la naturaleza bilateral correlativa de los derechos y deberes contractuales. La idea de que los terceros no pueden demandar ni ser demandados por el contrato se refleja en el llamado efecto relativo de los contratos.

Ahora, si pensamos en los contratos como una forma que las personas usan para disponer de sus bienes del modo que deseen, será evidentemente el caso que, en la medida en que un contrato se traduce en una redistribución de los bienes de una parte a la otra, la distribución de riquezas (bienes) en una sociedad se verá afectada cada vez que se celebra un contrato. Además, el hecho de que el incumplimiento de un contrato decepcione a terceros, tal vez de algún modo relacionados con la víctima de la violación, puede tener efecto en la distribución global de riquezas (bienes). Estas preocupaciones distributivas, creo, llevaron a KRONMAN y a otros autores a decir que el derecho contractual debería ser entendido en términos de justicia distributiva ${ }^{36}$. En la próxima sección, sostengo que, aunque parezca que la libertad contractual puede llevar a injusticias distributivas, no debe necesariamente hacerlo.

\subsection{Derecho contractual y justicia distributiva}

En el marco de la división de la responsabilidad, cuando intercambiamos bienes el uno con el otro, podemos terminar mejor o peor, pero eso será solamente una expresión de la idea de que, asumiendo que tenemos la cantidad justa de bienes sociales, se espera que asumamos responsabilidad por cómo sigue nuestra vida. Por ejemplo, no habría nada de malo si una persona pobre deja un reloj «Rólex» como regalo en la puerta de su adinerada estrella pop favorita. Como explica RIPSTEIN,

«[n] ada de esto es inconsistente con la idea que RAWLS defiende en liberalismo político, según la cual los efectos agregados de las transacciones individuales pueden llevar a injusticias en los bienes que necesitan ser encaminados.

El punto es simplemente que la necesidad de dirigir esas desigualdades de ningún modo socava la importancia de las transacciones particulares en la relación entre bienes primarios y libertad» ${ }^{37}$.

La división de responsabilidad, a su vez, conduce a algo que he mencionado anteriormente, esto es, a lo que RAWLs llama la división institucional del trabajo. Según él,

«lo que buscamos... es una división institucional del trabajo entre la estructura básica y las reglas que se aplican directamente a individuos y asociaciones y que ha de ser seguida por ellas en las transacciones particulares. Si esta división del trabajo se establece, los individuos y las asociaciones son libres para avanzar en sus objetivos de manera más eficaz en el marco de la estructura básica, con la seguridad de que, en el resto del sistema social, las correcciones necesarias para preservar la justicia de fondo se están realizando» ${ }^{38}$.

De acuerdo con este punto de vista, deberíamos tener instituciones separadas a cargo de tareas diferentes. El criterio para evaluar la equidad de un conjunto particular de instituciones sociales debería ser diferente del criterio según el cual juz-

\footnotetext{
36 Ver KRONMAN, nota, supra 3.

37 RIPSTEIN, nota, supra 27, pp. 1838-1839.

38 RAWLS, nota, supra 2, pp. 268-69.
} 
gamos la equidad de transacciones contractuales particulares. Sin embargo, esto no significa que las interacciones contractuales no tengan consecuencias distributivas, o que las consecuencias distributivas que puedan tener deben ser dejadas intactas. RAWLS dice que, una vez que la división del trabajo está en práctica, no debe exigirse a los individuos y las asociaciones que se ocupen de los efectos distributivos de sus transacciones. Ello es así porque la distribución resultante recibe ajustes constantes — por ejemplo, mediante el sistema impositivo ${ }^{39}$ —. Estos ajustes no tienen la forma de lo que R. Nozick ha llamado «interferencias continuas» con los planes y las acciones de los individuos ${ }^{40}$. Los individuos son conscientes de que son parte de un esquema de cooperación social por el cual su propiedad y riqueza puede estar sujeta a fiscalización; están familiarizados con el sistema de reglas públicas y, por lo tanto, toman esas reglas en cuenta cuando desarrollan sus planes ${ }^{41}$. Esto está relacionado con la concepción política de la persona que he explicado antes: las personas tienen un sentido de la justicia y, por eso, son conscientes del hecho de que, como parte de sus deberes para con la sociedad, se les puede pedir que apoyen a las instituciones justas.

Además, RAWLS argumenta que el conjunto de reglas que gobiernan las transacciones entre individuos y asociaciones, por ejemplo, las reglas contractuales de coacción y fraude, deben «satisfacer los requerimientos de simplicidad y practicidad», esto es, que «están diseñadas para dejar a los individuos y a las asociaciones libres de actuar eficazmente en la búsqueda de sus fines y sin limitaciones excesivas» ${ }^{42}$. RAWLS sugiere que las reglas que gobiernan los acuerdos no deben ser demasiado complejas porque el esquema de reglas no debe exceder la capacidad de los individuos de captar y seguirlas con suficiente facilidad ${ }^{43}$. También acepta que si los individuos fueran a pensar en los efectos distributivos de toda transacción en la que entren o que podrían tener, probablemente tendrían que discutir los términos de un acuerdo particular con todos aquellos que puedan verse afectadas por la transacción en cuestión. Por ejemplo, cuestiones relacionadas con externalidades surgirían todo el tiempo. Así, puede ser prácticamente imposible hacer que todos los individuos tomen en cuenta todos los efectos posibles de los contratos que concluyen. Pero incluso si no fuera prácticamente imposible, obligar a que los tomaran en cuenta aumentaría los costos de transacción a un grado indeseado. Los individuos verían a las reglas contractuales como una carga pesada que se les impone y con la cual no estarían dispuestos a lidiar, es decir, no verían al derecho contractual como una herramienta para perseguir su concepción del bien; más bien, como dice RAWLS, contratar cargaría a los individuos con «requisitos de conocimiento y previsión que no podrían normalmente satisfacer» ${ }^{44}$. Todo esto es cierto. En parte, es por estos efectos que RAWLS propone la división del trabajo. Pero esta no es la historia completa. Estos son todos «efectos secundarios» positivos de institucionalizar una división del trabajo. Pero el rationale rawlsiano para la división del

39 Ibid.

40 Para una discusión del argumento de Nozick, ver M. Hevia y E. Spector, «The Bizarre World of Historical Theories of Justice - Revisiting Nozick's Argument», 2008, Social Theory and Practice, 34 , p. 533.

41 RAWLS, nota, supra 7, pp. 51-52.

42 RAWLS, supra, nota 2, p. 268.

43 Ibid.

44 Ibid. 
trabajo puede explicarse en términos de las dos dimensiones diferentes de la división de responsabilidad que introduje antes.

\section{PARTE SEGUNDA}

\subsection{El estándar objetivo de interacción: la persona razonable}

Anteriormente en este trabajo, defendí una concepción política de la persona. Siguiendo a RAWLS, sostuve que la responsabilidad es una cuestión «política» y no de la metafísica. Según RAWLS, en una concepción política de la persona, las personas son libres en el siguiente sentido: tienen la capacidad de formar, revisar, y de perseguir racionalmente una concepción de lo bueno. Y, dado que son libres en este sentido, pueden ser consideradas responsables de las decisiones que toman y por aquello que hacen o dicen mientras persiguen sus planes de vida. Como ya sabemos, según esta concepción de la persona, las personas son racionales no sólo porque son capaces de adoptar ciertos fines sino también porque son capaces de elegir los medios más efectivos para perseguir los fines que adoptan. Además, en el esquema rawlsiano, las personas no son sólo racionales sino también razonables. Tomar a las personas como individuos razonables significa que, cuando las instituciones sociales son las apropiadas, esto es, cuando las personas reciben su porción justa de bienes primarios, se asume que los individuos son capaces de moderar los reclamos que hacen frente a las instituciones sociales de acuerdo con la parte justa de bienes primarios que razonablemente pueden esperar recibir. Además, tomar a las personas como personas razonables también significa que, dado que las personas privadas son libres de perseguir sus distintos fines, pueden hacerlo siempre que permitan a los otros perseguir sus propios planes al mismo tiempo.

Otra diferencia entre lo racional y lo razonable, que es particularmente importante para mis propósitos en este trabajo, es que lo racional no es público: rige para agentes únicos y unificados -individuos o personas corporativas- que persiguen sus propios intereses. En cambio, lo razonable tiene un carácter público que lo racional no tiene. Como explica RAWLS, «la razonabilidad lleva a los agentes al mundo de los otros, donde se convierten en iguales, listos para proponer o aceptar términos justos de interacción» ${ }^{45}$. Estos términos de interacción justa son términos que los agentes comparten y reconocen públicamente frente a otros. Según RAWLS, los agentes razonables

«Están listos para elaborar el modelo para el mundo público social, un modelo que resulta razonable para esperar el apoyo y actuación de todos, siempre que se pueda confiar en otros para que hagan lo mismo. Si no se puede confiar en ellos, entonces sería irracional o auto-sacrificante actuar sobre la base de esos principios. Sin un mundo público establecido, lo razonable podría ser suspendido y deberíamos quedarnos en gran medida con lo racional...» ${ }^{46}$.

Una consecuencia de esta concepción de la persona es que la idiosincrasia particular de los individuos no puede determinar unilateralmente las condiciones de las interacciones entre ellos: no es justo hablar meramente desde el punto de vista subjetivo de

\footnotetext{
45 RAWLS, supra, nota 2.
}

46 Ibid, pp. 53-54. 
un agente - eso implicaría el predominio de lo racional, incluso donde podría haber un racional «altruista»—. En este modelo rawlsiano, el Derecho privado se ocupa de lo que es apropiado como estándar de comportamiento para los individuos en interacción con otros en lugar de lo que cada individuo cree que es justo. Los pensamientos de una persona, sus motivos para actuar de un determinado modo son completamente irrelevantes para el Derecho privado. El Derecho sólo se ocupa de lo que los individuos hacen o dicen. Además, el Derecho interpreta esas acciones o palabras a la luz de un entendimiento públicamente accesible, o (objetivamente) razonable ${ }^{47}$.

Por supuesto, existen diversas razones para preferir un estándar objetivo en vez de uno subjetivo. Por ejemplo, si se adoptara un estándar subjetivo para determinar si las partes en un contrato han consentido, sería difícil mantener rastro de los pensamientos de cada una de las otras personas. Pero la cuestión no es esa. El argumento sostiene que los estándares públicos van de la mano de la idea de que los individuos interactúan bajo términos justos de interacción. Estos términos justos de interacción son términos razonables ${ }^{48}$. Son estándares que, por su propia naturaleza, son públicos e impersonales. Es por eso que, cuando los individuos interactúan en condiciones justas, lo hacen como iguales. Si para determinar si se celebró un contrato o no se le da más importancia al estado mental subjetivo de una de las partes que al de la otra, el Derecho estaría tratando a las partes de modo desigual. En cambio, tratar a las partes como iguales implica que adoptemos estándares públicos objetivos, estándares que puedan ser entendidos por ambas partes.

Cuando se trata de la celebración de acuerdos, los estándares públicos son importantes por la siguiente razón. Los contratos involucran a dos o más partes que consienten. En este modelo, el consentimiento tiene una naturaleza pública. Si una persona acepta una oferta mediante la firma de un contrato, pero en secreto piensa que no ha consentido al contrato, entonces, contra lo que piensa, ha consentido. Del mismo modo, la persona que rechaza una oferta, digamos, diciendo «no» a la otra parte, y, mentalmente, piensa que ha consentido, no lo ha hecho. Este será siempre el caso a menos que ambas partes sepan que, cuando el oferente dice «sí», significa «no», y cuando dice «no», realmente quiere decir «estoy de acuerdo». De nuevo, este estándar objetivo para la formación del contrato está atado a la noción de lo razonable. El estándar apropiado para la formación del contrato es un estándar de comportamiento que resulta justo para los individuos en interacción con otros.

Este enfoque de las personas es familiar para los abogados: es lo que en el common law se conoce como el estándar de la persona razonable.

O. W. Holmes Jr. es famoso —entre otras razones- porque promovió este estándar en el Derecho privado, que ejemplificó con responsabilidad en el derecho de daños. Para Holmes, el estándar es el estándar objetivo de los vecinos razonables:

«Si... un hombre nace torpe y apresurado, si siempre tiene accidentes y se lastima o lastima a sus vecinos, no hay duda de que sus defectos congénitos estarán permitidos en los tribunales del Cielo, pero sus golpes y caídas no serán menos problemáticos para sus

47 Ver B. CHAPMAN, «Rational Choice and Reasonable Interactions», 81, Chicago-Kent L. Rev., 75, 2006, p. 79.

48 Ripstein, supra, nota 5, p. 206. 
vecinos que si surgen de su negligencia culpable. Sus vecinos le exigen en consecuencia, a su propio riesgo, que se acerque a su estándar, y los tribunales que los vecinos establecen se oponen a tomar en cuenta la ecuación personal de riesgo de dicho individuo» ${ }^{49}$.

Como sugiere el párrafo, uno de los objetivos de Holmes fue distinguir el Derecho de la virtud moral. Tal como explican muchos comentaristas, este problema preocupó también a KANT ${ }^{50}$. En su Doctrina del Derecho, KANT sostiene que al Derecho le concierne solamente lo que él llama «el principio universal del derecho», o la coexistencia de la libertad de todos de acuerdo con la ley universal. Según KANT,

«[e]l concepto de derecho... tiene que ver... con la relación externa... de una persona con otra, en la medida en que sus acciones, como hechos, puedan tener influencia (directa o indirecta) en cada una de ellas» ${ }^{51}$.

Cuando el estándar de la persona razonable se aplica a la formación de un contrato, el resultado es que el contenido de derechos y deberes que nacen del contrato está determinado no por una las partes tomada aisladamente de la otra sino por la interacción entre ambas. El examen apropiado para determinar si se formó un contrato es un examen objetivo:

«El contenido del derecho [personal] no depende de lo que hagan las partes por separado sino de su iteracción... para determinar si el demandante tiene un derecho oponible al demandado que le da derecho al primero a destinar la cosa debida para un fin determinado es necesario ver si tal fin es tal que es razonable pensar que las partes debían contemplarlo cuando celebraron el acuerdo en el contexto en el que su interacción particular está situada dadas las circunstancias que los rodean» ${ }^{52}$.

A esta altura, tendría sentido preguntarse si hay algo especial sobre los contratos que los haga diferentes de cualquier otro tipo de interacción entre dos o más partes. Tomen, por ejemplo, una conversación ordinaria entre dos individuos. En ese escenario, ambos usan pistas contextuales para entender lo que el otro quiere decir. Esas pistas vienen de las otras cosas que se dicen el uno al otro y del mundo ordinario que comparten. Es así como llegan a entenderse en un lenguaje que puede resultarles extraño y que cualquiera de las partes puede estar usando, o una palabra que resulta familiar pero que es utilizada para referirse a algo distinto. En algún sentido, este tipo de interacciones son como el tipo de interacciones que surge entre las partes en un contrato. Entonces, tiene sentido preguntarse por qué el Derecho exige más de las partes en un contrato si, después de todo, como en una conversación ordinaria, se trata de dos partes que están haciendo algo juntas. El punto es, entonces, entender qué tiene de distintivo celebrar un contrato.

La diferencia entre las conversaciones ordinarias y los contratos es que los contratos generan obligaciones vinculantes, esto es, obligaciones exigibles. En una conversación ordinaria, pueden surgir muchos malentendidos. Pero no hay necesidad de

49 Ver O. W. Holmes, The Common Law [1881], Boston, Little Brown, 1963, pp. 86-87.

50 Ver B. Chapman, supra, nota 48, p. 78; A. RIPSTEIN, «Kant Law and Justice» [forthcoming]; C. VALCKE, «The Common Will of Offer and Acceptance», Nexus Magazine, 2005, p. 37.

${ }_{51}$ I. KANT, The Metaphysics of Morals, M. GREGOR (ed.), Cambridge, UK, Cambridge University Press, 1996, pp. 23-24.

52 Ver P. Benson, «Philosophy of Property Law», en J. Coleman y S. Shapiro (eds.), The Oxford Handbook of Jurisprudence and Philosophy of Law, New York, Oxford University Press, 2002, 752, pp. 785-786. 
llegar a una solución determinada para que las partes puedan entenderse; es más, no hay siquiera necesidad de tener una pista acerca de cómo la conversación va a continuar porque, justamente, se trata simplemente de una conversación ordinaria. En una conversación, el modo en que podemos tener éxito es averiguando lo que es razonable. Cuando la gente habla entre sí, trata de encontrar un mundo común al cual puedan referirse en su conversación. El Derecho exige más porque autoriza el uso de la fuerza. La mera coincidencia es, en consecuencia, insuficiente para el Derecho.

Dado que los contratos crean obligaciones vinculantes y exigibles para las partes, tienen que ser consistentes con su igual libertad, esto es, tienen que ser consistentes con otros individuos con derechos en un sistema de igual libertad. En el modelo de la división de responsabilidad, el uso de la coerción sólo está justificado cuando es compatible con un sistema de igual libertad. Consideren ahora el derecho de daños. En el derecho de daños, la adopción de un estándar subjetivo favorecería a los demandados porque, como defensa, un infractor podría alegar algo así como «no quise hacer eso» o «no sabía que estaba haciendo eso». Esto implicaría la aplicación de términos unilaterales de acción, incompatibles con la igual libertad: los demandados estarían imponiendo los términos de interacción al demandante. En un contrato, la situación es diferente. Presumiblemente, cada una de las partes en el contrato tiene un entendimiento subjetivo del acuerdo. Si este es el caso, entonces, un estándar subjetivo no es realmente una opción disponible: en un contrato, habría dos subjetividades compitiendo. Pero si el derecho hace cumplir el deseo de una de las partes, nuevamente, estaría imponiendo términos unilaterales de interacción, que permiten a la parte cuyo deseo prevalece, dominar aquel de la otra parte. El uso de la coerción para cumplir tal contrato, entonces, sería incompatible con un sistema de igual libertad.

Es por eso que, en consecuencia, el examen para determinar si se celebró o no un contrato se basa en lo que una persona razonable hubiera querido decir por cada cosa que las partes dijeron o hicieron. Pero la referencia a las personas razonables no se debe a que la razonabilidad sea algo que necesariamente deba alentarse, o porque la razonabilidad pueda tener otros efectos deseados. En cambio, la referencia se debe simplemente a que de eso se trata en un acuerdo vinculante.

Para una teoría objetiva de los contratos, entonces, el test para determinar si se ha formado un contrato y en caso de que se haya formado, cuáles son sus cláusulas, se basa en mutuas «declaraciones de intenciones» de las partes. Esas declaraciones pueden ser explícitas o implícitas. En contraste, las teorías subjetivas de los contratos sostienen que los contratos se forman sobre la base de lo que las partes realmente quisieron hacer. Pero, desde una aproximación objetiva, los pensamientos «internos» de las partes no juegan ningún papel en la determinación de la existencia o el contenido de un contrato.

Ahora permítanme ilustrar mi punto haciendo referencia a un famoso caso, Smith C/ Hughes ${ }^{53}$. Los hechos de ese caso son, en pocas palabras, del siguiente modo. El demandante, un granjero, le llevó algo de avena a Hughes, el gerente de la demandada, que era dueño y domador de caballos. El demandante dijo haber dicho «tengo buena avena a la venta» y cuando Hughes contestó «siempre estoy dispuesto a comprar bue-

53 (1871). L. R. 6 Q.B., p. 597. 
na avena», ofreció de cuarenta a cincuenta cuartos a 34s. A cambio, el demandante le envió a Hughes dieciséis cuartos, quien se quejó porque eran nuevos. El demandante admitió que eran granos nuevos y negó tener avena vieja. En la apelación la cuestión fue la siguiente: en base a los hechos del caso, ¿era más razonable para el vendedor que la orden involucrara viejos granos? ¿O era más razonable creer que se trataba de granos nuevos basados en la muestra? HANNEN J. famosamente notó que la capacidad de cualquier parte contratante para atribuir significado a otra parte contratante depende de cómo una persona razonable entendería lo que dice su contraparte... Como explica B. CHAPMAN,

«Si ambas partes tienen un contrato por la venta de, digamos, "granos nuevos" o "granos viejos" no dependerá de si existe un encuentro (o superposición) de sus mentes (privadas) sobre el tema en cuestión. Más bien, un tribunal asistirá al entendimiento público más plausible de la transacción y considerará al contrato referido a los "granos viejos" si ese es el significado más razonable (objetivamente) de sus términos en el contexto en el cual ha ocurrido» ${ }^{54}$.

Smith c/ Hughes muestra que una sociedad en donde las interacciones entre individuos están gobernadas por condiciones justas de interacción requiere un examen objetivo para determinar si se han creado obligaciones vinculantes y exigibles. No sería justo justificar el uso de coerción en el caso de un incumplimiento sobre la base de un estándar que sólo responde a los deseos de una de las partes.

Ahora, si bien estoy defendiendo un enfoque objetivo del derecho de los contratos, no todos los sistemas legales están pensados desde un enfoque similar. Por ejemplo, los juristas franceses generalmente sostienen que el Derecho privado francés es mucho más subjetivo que el del common law. Los tratados franceses de Contratos dicen que la base de las obligaciones contractuales es la autonomía de la voluntad. En el Derecho privado francés la noción de consentimiento es subjetiva al extremo: sólo la voluntad del individuo es vinculante. La interpretación que los otros puedan hacer de esa voluntad, o la reconstrucción de esa voluntad por el Derecho no es vinculante. Para los juristas franceses, sólo importa la voluntad interna y subjetiva del individuo -la volonté psychologique («voluntad psicológica»). Este papel fundamental de la noción de autonomía como fundamento de las obligaciones legales voluntarias es, posiblemente, un producto del individualismo económico y filosófico del siglo XIX ${ }^{55}$.

54 Ver Chapman, supra, nota 48, p. 79. Para un ejemplo del enfoque subjetivo, ver Dickinson v. Dodds, 1876, 2 Ch. D. 463 (C.A.), que usualmente es utilizado como ejemplo de una teoría subjetiva de los contratos y de la formación de los contratos en particular. En ese caso, el tribunal sostuvo que ningún contrato de compraventa se había formado entre las partes porque, cuando el oferente pretendía aceptar la oferta, ya sabía que el ofertante no tenía la intención de venderle. Las intenciones privadas de las partes resultaron externamente visibles en el caso. El oferente Dickinson había sido informado por alguien del hecho de que Dodds, el ofertante, había ofrecido vender la propiedad o acordado vendérsela a otra persona. La oferta había sido retirada pero Dickinson no había notificado formalmente a Dodds sobre esto. El hecho de que no fuera el ofertante sino alguien más quien informaras al oferente del retiro de la oferta fue considerado irrelevante.

55 Tomé esta idea de C. VALCKE, «Comparative Law as Comparative Jurisprudence - Objectivity and Subjectivity in the English, French, and German Law of Contractual Mistake» (trabajo presentado al Special Workshop on Ethics, Economics and the Law en el XXII Congreso Mundial de Filosofía del Derecho y Filosofía Social, mayo de 2005) [sin publicar]. Para puntos similares, ver también, J. HauSER, Objectivisme et Subjectivisme Dans L'Acte Juridique, París, Librairie Générale de Droit et de Jurisprudence, 1971. 
Aunque el enfoque de los juristas franceses es subjetivo, los tribunales franceses han enfocado la cuestión desde una perspectiva objetiva. Por ejemplo, cuando discuten cuestiones de formación de contratos, esto es, si hay una escisión entre las declaraciones de las partes y sus intenciones subjetivas, los tribunales franceses tienden a no mirar las intenciones subjetivas: adoptan argumentos de construcción de la voluntad de las partes. Tomen, por ejemplo, la noción de error. Valcke explica que lo que determina si el derecho contractual de un sistema legal en particular es objetivo o subjetivo es el enfoque adoptado por ese sistema respecto de los errores contractuales. Un entendimiento subjetivo de los contratos usualmente libera a la parte equivocada: la voluntad subjetiva de la parte equivocada prevalece sobre su declaración externa y objetiva. Por el contrario, un enfoque objetivo del derecho contractual ataría a la parte equivocada a sus obligaciones: su declaración externa prevalecería por sobre su voluntad subjetiva. En la práctica, cuando los tribunales franceses analizan si un determinado error de una de las partes vicia su consentimiento y, consecuentemente, anula el contrato, adoptan un enfoque objetivo: dicen que el error debe ser excusable y relacionado con una característica del acuerdo que la otra parte sabía o debió saber era determinante para la parte que comete el error. La inclusión de estas dos condiciones hace al enfoque francés de los contratos, al menos respecto a los errores, más objetivo que subjetivo: desde una visión subjetiva, sólo importa la existencia del error y las circunstancias bajo las cuales el error nace son irrelevantes. Pero esto no es, sin embargo, lo que los tribunales franceses dicen ${ }^{56}$.

Como respuesta a esta objeción, algunos juristas franceses argumentan que el enfoque objetivo es adoptado sólo porque

«Las intenciones individuales no son siempre fáciles de descubrir... además, como la intención es un elemento que puede interpretarse de diferentes modos, ciertas cláusulas serían interpretadas de modo distinto por tribunales diferentes... Estas objeciones se relacionan más con las dificultades prácticas en la aplicación de nuestra teoría que por la teoría en sí misma» ${ }^{57}$.

Los juristas franceses tienen razón cuando señalan lo difícil que resulta meterse en las mentes de las partes para descubrir qué es lo que quisieron hacer cuando actuaron de un determinado modo: es una preocupación legítima. Pero esa no es la razón por la que debería adoptarse un enfoque objetivo. Si los contratos son resultado de que dos o más partes se reúnen para lograr algo en común, ¿por qué debería prevalecer la voluntad de una de las partes por sobre la voluntad de la otra? Como he dicho antes, dado que los contratos son esfuerzos cooperativos, la existencia y el contenido de un contrato están determinados no por alguna de las partes tomada aisladamente sino por su interacción. No se trata de negar que el consentimiento es el aspecto central de un contrato, es decir, que la justificación para contratar es que se trata de una herramienta para los individuos que voluntariamente participan en cooperación con otros. Si el consentimiento no fuera tenido en cuenta, las partes se verían obligadas a conferir beneficios a otros individuos. Y eso, por supuesto, sería problemático. ¡Pero el consentimiento también es objetivo! Supongan que una de las partes en un acuerdo

56 Ibid.

57 J. CHABAS, De la declaration de volonté en droit civil francaise, pp. 81-81, Syrey, 1931, citado en VALCKE, supra, nota 56. 
dijera que no quiso decir algo, o que no quiso hacer algo que hizo porque «pensó» que estaba haciendo otra cosa, o que no pudo imaginar que sus palabras serían entendidas del modo en el que la otra parte lo hizo. Si en estos casos, y meramente por estos pensamientos internos de la parte «equivocada», se garantiza el perdón, entonces no habría nada de malo en dejar que una de las partes en un contrato establezca los términos de interacción unilateralmente. Sin embargo, desde la perspectiva rawlsiana que adopto en este ensayo, permitir a una de las partes establecer los términos de interacción unilateralmente resulta irrazonable. Eso sería problemático porque dejaría a una de las partes totalmente a merced de los caprichos de la otra parte. A la luz de esto, en el modelo rawlsiano, el Derecho privado se preocupa por lo que es apropiado como estándar de comportamiento con individuos en interacción con otros en lugar de lo que los individuos por separado consideran justo. Y esto es así porque los estándares públicos reflejan la idea de que individuos iguales interactúan en términos de condiciones justas de interacción. Desde este punto de vista, por supuesto, el consentimiento importa, pero se lo entiende en términos públicos.

\subsection{Algunas objeciones}

En contra del estándar de la persona razonable, podría decirse que no es más que una mera descripción de la persona ordinaria que no deja en claro qué cualidades de persona «razonable» real son relevantes normativamente y cuáles no lo son. Por ejemplo, algunos comunitarios han argumentado que la concepción de los agentes reflejada en el estándar de la persona razonable se basa en una concepción de la persona que se desprende de argumentos basados en la idea de «contrato social» que estructuran las relaciones de los individuos de un modo particular ${ }^{58}$. Para los comunitarios, el problema es que no tiene sentido hablar de un «contrato social» entre extraños:

«Nuestra propia existencia e identidad como agentes y, por tanto, como ciudadanos que están sujetos a la ley, depende en las relaciones sociales afectivas que los individualistas liberales relegan a la esfera "privada" ${ }^{59}$.

Para los comunitarios, la sociedad no es una colección de extraños que sólo acuerdan respetar los derechos de cada uno; en su opinión, la sociedad es una comunidad de «amigos» que se preocupan por el bienestar de los demás. Ahora, si nuestro interés en cada uno como conciudadanos no es sólo el interés que los extraños pueden tener sobre la base de un contrato sino en los intereses que los colegas de una comunidad tienen el uno con el otro como «amigos», entonces la noción legal de responsabilidad a la que estamos acostumbrados sería bastante diferente. Dado que los comunitarios ven a las personas como «amigos», lo que importa para ellos no es sólo la conducta que las personas muestran en público, sino los rasgos de carácter más profundos y complejos de los cuales fluye la conducta. Tales rasgos determinan la naturaleza de las relaciones

58 Para ésta objeción, me basé en R. A. DuFf, «Choice, Character, and Criminal Liability», 1993, 12, Law and Philosophy, 345, p. 381. En este trabajo, Duff discute - aunque no en profundidad- concepciones individualistas y comunitarias de la responsabilidad criminal. Encuentro útil la explicación de DuFf respecto a alguno de los principios comunitarios básicos para el punto que trato de desarrollar.

59 Ibid., p. 382. 
sociales. Para los comunitarios, entonces, no hay diferencia entre la conducta que infringe los intereses relevantes de los otros y las estructuras profundas de pensamiento y sentimiento que constituyen el carácter de individuos que interactúan. Desde este punto de vista, el carácter moral de una acción no depende de los efectos que esa acción puede tener sobre otros, sino de los rasgos de carácter del agente que la acción en cuestión manifiesta ${ }^{60}$. Para los comunitarios, como miembros de la comunidad, necesitamos desarrollar y mantener las actitudes apropiadas hacia nuestros conciudadanos. En esta visión, el Derecho es un instrumento que está comprometido con criticar y corregir disposiciones morales incorrectas de los individuos ${ }^{61}$.

Para los comunitaristas, entonces, toda interacción humana, incluidas las relaciones jurídicas tales como aquellas entre las partes en un contrato, deberían apuntar en última instancia a que las personas se sientan cerca una de la otra. Desde esta visión, un acuerdo sería vinculante sólo si promueve vínculos especiales entre las partes contratantes ${ }^{62}$. Contra esta visión, D. KIMEL ha argumentado que el valor de contratar reposa en que los contratos promueven desapego antes que relaciones personales: los contratos sirven para participar en relaciones con otras personas que no exigen el tipo de compromiso personal que, digamos, exigen las promesas. KIMEL da un muy buen ejemplo al respecto. Supongan que el Decano de una determinada universidad es amigo de uno de los profesores, a quien le ofrece un puesto de mayor jerarquía dentro de la Facultad. El hecho de que sean amigos hace que las cosas sean un poco más complicadas para el Decano. En consecuencia, le ofrece al profesor un contrato para firmar, en el cual los derechos y obligaciones de ambas partes están claramente determinados. En este caso, recurrir al Derecho contractual permite que ambas partes separen su amistad de su relación laboral: promueve el desarrollo personal de los deberes particulares en juego en la relación laboral ${ }^{63}$. En verdad, no es necesario ir tan lejos. A fin de que el Derecho contractual tenga sentido, sólo es necesario probar que, al menos, la posibilidad de contratar es consistente con la igual libertad de las partes. Por supuesto, los comunitarios pueden insistir en que el Derecho debería promover ciertos rasgos de carácter. Pero, si ese fuera el caso, entonces, estaría más claro quien está estancado en esa posición.

Además, no es verdad que la concepción rawlsiana de la persona como persona razonable, niegue la importancia de valores comunales. Por ejemplo, RAWLS está de acuerdo con uno de sus críticos, M. SANDEL, en que esos valores florecen en el contexto de diferentes tipos de asociaciones, la vida familiar, las iglesias, y demás ${ }^{64}$. Pero la identidad legal de una persona (por ejemplo, sus deberes y derechos) no debería depender de si las personas aprueban una determinada concepción del bien. Desde la

${ }^{60}$ Ibid., p. 362.

${ }^{61}$ Ibid., pp. 382-383.

62 Este argumento también ha sido desarrollado por escritores no-comunitarios. Vid., por ejemplo, S. A. SMITH, «Performance, Punishment and the Nature of Contractual Obligations», Mod. L. Rev., 370, 1997, p. 60.

${ }_{63}$ Vid., en general, D. KimeL, From Promise to Contract — towards a liberal theory of contract, Oxford, Hart Publishing, 2003.

${ }^{64}$ RAWLS, supra, nota 2, pp. 139-140 y 217. Para una discusión de este punto, ver S. MulHALl y A. SwIFT, «Rawls and Communitarianism», en S. FrEEMAN (ed.), The Cambridge Companion to Rawls, Cambridge, UK, Cambridge University Press, 2003, pp. 460-466. 
perspectiva rawlsiana, lo que importa es que incluso si mi concepción del bien resulta no ser la mejor para mí, sigue siendo lo que yo quiero hacer de mi propia vida y, dado que tengo un poder moral para establecer y perseguir mi propia concepción del bien, debo hacerme responsable de cómo continua mi vida.

En verdad, lo que realmente está en juego es si los comunitarios pueden proporcionar una justificación mejor para el uso de coerción. Los comunitarios tienen que probar por qué se justifica el uso de la coerción para promover — sino para imponeruna cierta concepción del bien. Todavía no lo han hecho. En cambio, los rawlsianos tienen una explicación para el uso legítimo de la fuerza, que es la idea de que cualquier restricción a la libertad debe justificarse sobre la base de un modelo de límites recíprocos.

Tampoco es cierto que si se adoptara el estándar de la persona razonable, las concepciones del bien que ven a las relaciones con otros como poseedoras de un valor intrínseco pasarían a tener menos valor. Precisamente, el estándar de la persona razonable ofrece una respuesta a esta preocupación porque toma seriamente el hecho de que los individuos no están aislados sino que viven juntos en una sociedad. Dicho estándar está basado en la reciprocidad. Y la reciprocidad implica tomar los intereses de otras personas seriamente: lo que expresa el estándar es una idea de términos justos de interacción. El punto es que las personas razonables comparten su concepción de interacción pública razonable. Luego, por supuesto, son libres de adoptar lo que podríamos llamar formas de cooperación «sustantivas» si encuentran otras personas que deseen reunirse con ellos para hacerlo. Como sostiene RAWLS,

«Las personas razonables [están movidas por un deseo por] un mundo social en el cual puedan, como individuos libres e iguales, cooperar con otros en los términos que acepten. Insisten en que la reciprocidad debería mantenerse dentro de ese mundo de manera que cada uno puede beneficiarse junto con otros» ${ }^{65}$.

De hecho, según esta concepción de la persona, los individuos deberían compartir metas. RAWLS explica que las personas razonables comparten

«... el objetivo de asegurar que las instituciones políticas y sociales sean justas, a la hora de hacer justicia frente a las personas en general, frente a los que lo ciudadanos necesitan para sí y lo que quieren para los demás. No es verdad, entonces, que desde una visión liberal los ciudadanos no tienen objetivos comunes fundamentales. Ni es verdad que el objetivo de la justicia política no es una parte importante de su identidad no-institucional o moral» ${ }^{66}$.

Otra preocupación con el estándar de la persona razonable involucra cuestiones de género ${ }^{67}$. En general, los feministas han criticado el uso de estándares objetivos para evaluar el comportamiento. Algunas feministas han propuesto estándares subjetivos con la esperanza de que hagan más igualitarios a los estándares legales de comportamiento. En algún sentido, estas objeciones son justas, sobre todo teniendo en cuenta las tendencias de algunos tribunales de «confundir» a la persona razonable con la per-

65 RAWLS, supra, nota 2, p. 50

66 Ibid., p. 146, n. 13, citado en MulHall \& SwIFT, supra, nota 65, pp. 468-469.

67 Vid., en general, M. Moran, Retbinking the Reasonable Person, Oxford, Oxford University Press, 2003. Para una reseña interesante del libro de MORAn, ver J. HordER, «Can the Law Do Without The Reasonable Person?», U.T.L.J., 253, 2005, p. 55, . 
sona «ordinaria» ${ }^{68}$. Sin embargo, en primer lugar, las objeciones feministas parecen estar planteadas contra el modo en que los jueces ponen en práctica al estándar, pero no contra el estándar en sí mismo. El estándar refleja una concepción particular de igualdad que los feministas no niegan necesariamente. Es más, las preocupaciones sobre la mala aplicación de estándares objetivos también se aplica a estándares subjetivos. De hecho, esta es precisamente la razón por la cual los feministas generalmente piensan que es peligroso aplicar estándares subjetivos para determinar si se cometió una violación, digamos. Si todo depende de qué piensa un agente de sus propias acciones, o de cómo se siente respecto a sus acciones, siempre será posible alegar algo así como «no pensé que estaba haciendo eso» cuando cualquiera es acusado de la comisión de un crimen o de causar un daño.

Segundo, en respuesta a estas objeciones, también es importante tener en mente que el estándar de la persona razonable no es un estándar fáctico sino normativo. Eso significa que no representa a la persona ordinaria ${ }^{69}$. En cambio, el estándar va de la mano de una concepción determinada de la igualdad ${ }^{70}$. El esquema rawlsiano asume que las personas son libres e iguales. Son iguales en el sentido de que, como explica RAWLS, «todos ellos son considerados como poseedores de los poderes morales en el grado mínimo esencial para relacionarse en una cooperación social sobre una vida completa y de tomar parte en una sociedad como ciudadanos iguales ${ }^{71}$. Por supuesto, podría ser el caso que, dado que el estándar debe ser aplicado en última instancia por alguien, los jueces sean los encargados de hacerlo. Esto podría ser una invitación para que razonen sobre la base de un preconcepto de qué es lo «ordinario». Claro que eso podría ser cierto, pero no dice nada en contra del estándar — en todo caso, lo dice respecto de los jueces.

Además, como he argumentado antes, para el Derecho, los problemas filosóficos tales como la discusión acerca del libre albedrío son irrelevantes. El Derecho no debería resolver la cuestión de si las personas son verdaderamente libres, es decir, metafísicamente libres, cuando, por ejemplo, deciden celebrar un contrato. En suma, adoptar el estándar de la persona razonable no implica negar la posibilidad de aceptar que, en un sentido metafísico, las elecciones y las acciones están «socialmente» determinadas. Ello podrá ser cierto, pero, incluso teniendo en cuanta que la elección es central para el Derecho contractual, la cuestión acerca de si los actos de las personas están determinados socialmente o son producto del ejercicio del libre albedrío de los agentes es irrelevante para el Derecho. La responsabilidad jurídica no es una cuestión metafísica sino política.

\subsection{Observaciones finales}

Este ensayo presenta un enfoque rawlsiano del Derecho contractual. Como sabemos, J. RAWLS es uno de los filósofos políticos más influyentes de los últimos tiempos.

\footnotetext{
68 Moran, ibid.

69 RIPSTEIN, supra, nota 5, pp. 6-8.

70 Ibid.

71 RAWLS, supra, nota 7, p. 23.
} 
RAWLS estaba principalmente preocupado por lo que llama «la estructura constitucional esencial», es decir, no buscaba una justificación para el uso de la coerción para hacer ejecutables los acuerdos entre los individuos. Tal vez es por eso que no dijo mucho respecto de los principios que animarían al Derecho privado ${ }^{72}$. En este artículo, uso la idea de una división de responsabilidad entre la sociedad y los individuos para ofrecer un enfoque normativo rawlsiano del Derecho contractual. En el modelo de la división de responsabilidad, la justicia requiere que usemos la coerción sólo para hacer cumplir los términos justos de interacción. Por ello, las interacciones contractuales son interacciones razonables, esto es, interacciones basadas en términos públicos e interpersonales de interacción. En algún sentido, entonces, este trabajo es un intento de completar la obra de RAwLS.

\section{(Traducción de Emiliano Villa)}

72 En mi contra, podría señalarse que algunos pasajes de $A$ Theory Of Justice están dedicados a explicar la institución de la promesa. RAWLS explica que «[p]rometer es una acción definida por un sistema público de reglas» que son como las «reglas de los juegos». Los filósofos morales pueden explicar por qué, si alguien toma ventaja de una institución justa, aquél deberá cumplir con sus reglas. Desde esta visión, la razón por la cual debemos mantener nuestras promesas es que la institución social de la promesa es valiosa para la sociedad. Si no cumplimos con nuestras promesas, hacemos algo incorrecto, a saber, socavamos una práctica socialmente valiosa. Ver RAWLS, supra, nota 1, pp. 344-348.

En este trabajo, ofrecí razones para explicar por qué el enfoque basado en las promesas no nos ayuda a entender el Derecho contractual: acercarse al Derecho contractual desde la perspectiva de las promesas punto de partida equivocado: no nos ayudan a entender por qué, cuando incumplo mi contrato con mi contraparte, no estoy, digamos, simplemente aprovechándome gratuitamente de una convención socialmente valiosa, sino perjudicando a mi contraparte: al incumplir el acuerdo, estoy privando a mi contraparte de algo que ya le pertenece. Ver mi discusión de Contract as a Promise -A Theory of Contractual Obligation, de Ch. FRIED, Cambridge, Mass., Harvard University Press, 1981, en «Fuller, Fried, and the Nature of Contractual Rights and Duties» (manuscrito sin publicar). 